\title{
La Estela del Blitz: el constructo cultural británico tras la Segunda Guerra Mundial
}

\author{
Carlos NAVArro GonZÁLEZ \\ Departamento de Historia Contemporánea \\ Universidad Complutense de Madrid \\ canava01@ucm.es
}

\begin{abstract}
RESUMEN
Para Gran Bretaña la Segunda Guerra Mundial sigue siendo un sinónimo del Blitz (Blitzkrieg). La metrópolis quedó destruida por más de 18000 bombas entre 1940 y 1941, su identidad gravemente dañada y, con ello, se ponía fin a un período imperial que trastocaría irremediablemente las formas de comportamiento y expresión de toda la cultura británica. El sujeto cultural británico, tras el Blitz y la Segunda Guerra Mundial, se construiría literaria y artísticamente de una manera totalmente nueva y enraizada en unas concepciones surgidas del desastre. La literatura, el texto dramático y la poesía se edificaron a caballo entre el constructo cultural tradicional británico y una introspección individual del sujeto en el que este identifica a un «enemigo» externo y uno interno.
\end{abstract}

Palabras clave: Blitz, posguerra, Gran Bretaña, cultura, literatura, arte, cine.

\section{Trails of the Blitz: Postwar British cultural narratives}

\begin{abstract}
In the aftermaths of the WWI, Great Britain laid destroyed after a continuum of raids between 1940 and 1941. The Metropolis suffered deep transformations in its cultural and identity pillars affecting the dynamics of cultural expression itself. Postwar British cultural narratives would be raised onto new paradigms of comprehension rooted in disaster. Literature, Drama and Poetry flowed between traditional cultural narratives and a new-coined paradigm of understanding the subject.
\end{abstract}

Keywords: Blitz, postwar, Great Britain, culture, literature, art, cinema.

\section{Introducción}

Se suele aceptar sin premisas que la Segunda Guerra Mundial se encuadra en el continente europeo: con franceses, rusos y alemanes -dependiendo del momento de la trama que se relate- luchando en territorio propio y los ingleses y estadouniden- 
ses siendo aquellos que luchan en territorio ajeno. Esta simple percepción, no del todo acertada, casi de imaginario subconsciente, acarrea consigo un paradigma crucial de entendimiento de la guerra y la implicación del mundo anglosajón en el conflicto. ¿Qué papel juegan por tanto los británicos? ¿Con qué denominación cabría incluirles? ¿Qué rol les es más preciso sobre todo de cara a una evaluación de esquema comportamental?

Tenemos entre manos a un Imperio, el más vasto conocido hasta esa fecha en los tiempos modernos, aunque se trate de un imperio comercial, (Hobsbawm 2001:14) y que está siendo atacado por los nazis al igual que la práctica totalidad de las naciones europeas lo han sido o lo serán desde 1939 y hasta 1945. Cabe preguntarse de qué manera la Segunda Guerra Mundial marcó a los intelectuales y a la producción cultural en general de los propios británicos. Se trata del primer ataque sufrido en tierras británicas desde épocas de la Guerra Civil y la Revolución Gloriosa. Los paradigmas que pretendo tener en cuenta son: el declive del imperio, el enemigo externo inaprehensible (por su naturaleza aérea, por sus ataques fulminantes sin previo aviso ni tropas que defendieran a Gran Bretaña de sus bombardeos) y el enemigo interno, en forma de desempleo, hambre y desigualdad de clase así como un tradicionalismo particular (Caserio 2009) que proviene del enfrentamiento singular británico con el resto de culturas europeas que es, en definitiva, lo que les separa del continente. Desde cualquier arista del prisma cultural británico del que se mire, el bien más preciado que tiene dicha cultura es el de la insularidad, la diferenciación con respecto al resto del Viejo Mundo así como una senda histórica diferenciada que aumenta exponencialmente los kilómetros de ancho del Canal de la Mancha. Desde la última contienda librada en tierras británicas en 1688 y hasta el 7 de Septiembre de 1940 en que 647 aviones de la Luftwaffe sobrevolaron el East End de Londres, en el Reino Unido no hubo invasión o ataque extranjero alguno ${ }^{1}$. Además de todo ello, la Primera Guerra Mundial provocó un total de 17 millones de muertos, de los cuales casi 900.000 eran ciudadanos británicos; una cantidad de británicos muertos nunca antes asimilada y un shock para la sociedad de la época que seguía viendo, a pesar de todo, la guerra como un asunto extraterritorial. Casi un malsano complot de invenciones de la prensa ${ }^{2}$. Las diferencias entre británicos se daban en distintas escalas y relaciones de clase: entre Londres y el resto del Reino Unido, entre el Reino Unido y el resto del Imperio, entre colonos y esclavos, colonias blancas... el descontento no era baladí y en temas como el antiimperialismo y los «enemigos internos» de los que habla Orwell en 1984 a menudo confluían en los mismos sec-

${ }^{1}$ En ese mismo lapso de tiempo, el resto del continente geográfico europeo sufría (contando únicamente los enfrentamientos más importantes): 50 guerras entre Estados, 28 guerras civiles y 38 revueltas.

${ }^{2}$ La Primera Guerra Mundial nos trae un impasse, una excepción a esta «nunca antes hallada invasión extranjera en suelo británico»: 51 ataques alemanes trazando el pesado y torpe vuelo de los zeppelines alemanes, llamados baby-killers por su ineficacia y su lentitud. El «terror huno» que despertaron estos ataques pusieron en sobreaviso al imperio, creándose así la RAF (el cuerpo militar aéreo de Gran Bretaña) el 1 de Abril de 1918. Desde ese momento, el peligro para los británicos era alemán, incorpóreo y aéreo. 
tores reivindicativos. Casi como un avance común de componentes interrelacionales, la sociedad británica iba dejando atrás el siglo XIX; los mercados y productos cualesquiera que hubieran aportado tanto capital a Gran Bretaña en un aparente pasado mejor, como los astilleros, el carbón o el algodón ahora estaban en declive y era responsabilidad de los poderes políticos evitar que su colapso no repercutiera en el daño humano que, de hecho iba a infringir.

\section{Blitz}

Harold MacMillan, Primer Ministro británico, escribió en 1956: «Yo mismo y muchos otros que me rodeaban pensábamos en los ataques aéreos como hoy pensamos en la guerra nuclear». De una forma u otra, la guerra es un mal inherente al ser humano hasta donde llevamos demostrado. Las ciudades se arrasan y los ejércitos enemigos infunden el miedo de la mismísima muerte con el chapotear de sus botas. Los elemento conectores de ambos acontecimientos que menciona MacMillan son el miedo y el desconcierto. Las víctimas de un país desarrollado en términos comunes como Gran Bretaña tenía la certeza de que serían atacados por sus enemigos, sin embargo no se sabía cuándo ni por dónde y, para cuando esto fuera descubierto habría sido demasiado tarde como para reaccionar. Muerte y destrucción seguras. El miedo nuclear fue la patología que nunca llegó a expresarse fácticamente durante buena parte del siglo $\mathrm{XX}^{3}$; El miedo entre la población era intenso desde antes de la propia guerra y el gobierno (Fisher 2014: 65) puso en marcha un plan de reubicación poblacional a raíz del caos migratorio producido en 1938 por la celebración de los Acuerdos de Múnich y la anexión de los Sudetes por parte de Alemania. Un total de 150000 personas huyeron por su propio pie hacia Gales temiendo ataques sobre Gran Bretaña. Con el consiguiente plan reubicatorio se pensaba movilizar a casi 4 millones de personas de las ciudades al entorno rural para prevenir el desastre masivo. Aquellos que permanecieron en Londres tuvieron que continuar en constante amenaza de ataque ya que -pese al error de las predicciones- los ataques serían nocturnos y cerca de 160000 personas tuvieron que dormir en el metro. No se trataba de un refugio seguro en cualquier caso. La profundidad de las bombas a veces penetraba hasta el corazón de Ballham Station. Durante los bombardeos de la Luftwaffe, el espíritu de superación y perseverancia británicas por conservar la moral a menudo se encontraba en el fondo de una pinta.

Los londinenses y británicos en general mantuvieron un espíritu incluso aberrante (podría observarse desde fuera) en el que, arrebatando la dignidad al Blitz, los transeúntes llegaban a alegar que preferían la lluvia de bombas al clima británico «It is indeed very blitzy today» (Caserio 2009) El silencio que dejaron las bombas sobre

${ }^{3}$ El miedo al ataque aéreo en Gran Bretaña se cobró más de 40.000 vidas y más de un millón de edificios arrasados durante 57 noches consecutivas desde el 7 de Septiembre de 1940. En total fueron 71 ataques sobre Londres con 18.291 toneladas de explosivos en 128 ataques aéreos a lo largo de 267 días. (Field 2002: 183) 
Londres cambió Gran Bretaña entera. El hecho de que la metrópoli hubiera sido destruida significaba que el mismo imperio lo había sido. La cultura que emergió de las cenizas no pretendía alterar jerarquías pasadas para salir adelante (haría falta un relevo generacional para ello). Gran parte de los escritores, poetas y dramaturgos que sobrevivieron a los ataques y a la guerra habían comenzado a producir su objeto cultural antes de las bombas. En sus formas de expresión, como mímesis de la realidad más que nunca, la producción cultural se vio marcada incondicionalmente por la guerra y los escombros, por los compatriotas muertos pero también por todas las otras víctimas de la guerra. La producción cultural también arrastró viejas tendencias heredadas y aún supervivientes a la mayor crisis económica que se recordaba, a otra Guerra Mundial y al ocaso de un imperio. En cierta manera devenida de estas temáticas, resurge la del regionalismo y el fernweh, la saudade, la morriña; el culto al mapa, nostálgicamente hablando.

Casi como un salmo al conservadurismo cultural el «sense of regions» vino a representar el paradigma del carácter británico, internacional, transnacional y regionalista por la condición multinacional que tenía Gran Bretaña. Los antagonismos fantasmas producidos por los raids sobre el Reino Unido fabricaron literalmente un constructo antagónico inaprehensible en esencia para los británicos; por tanto, se acuñaron una serie de características en torno a «lo extraño» del miedo como unheimlich de su no organicidad. La indefensión a escala humana aminoró el avance del concepto de humano como dominador del medio y provocó una ruptura de cánones lógicos antagónicos siendo el propio ser humano quien había destruido cuanto había «dominado» previamente. Es, por tanto, una amenaza indetectable e inaprehensible y sobre todo identificada como externa. De este modo para identificar un entramado comportamental en la construcción cultural británica de posguerra tendremos en cuenta cuatro elementos: Imperio, Regionalismo, Unheimlichantagonismos fantasma y Enemigo interno.

\section{Regionalismo ${ }^{4}$}

En la expresión cultural británica es muy importante (no solo durante la posguerra) la concepción de unidad cultural (devenida del imperio) y la transnacionalidad como elemento transicional de dicha unidad. Lo reseñable no son en este caso las particularidades que, en detalle, convierten cada «región» en especial y diferenciable, sino en la unidad de todas ellas. Si Gran Bretaña es en origen histórico un archipiélago y su imperio es de «ultramar», el agua es lo que conecta todas sus islas. El agua es a la vez lo que particulariza cada singularidad de su cultura y a la vez une el archipiélago con el resto del mundo. Esta particularidad de expresión cultural tiene una tradición con orígenes anteriores a la Segunda Guerra Mundial; los románticos como Coleridge o Wordsworth enfatizaban la visión de paz y libertad asocia-

${ }^{4}$ Con el término «región», dentro de la producción cultural británica, podemos hablar igualmente de la escena poética de una ciudad así como de la poesía en los territorios de ultramar. 
da a la vida campestre ${ }^{5}$ (Alderman 2014). En 1983 Graham Swift en su novela Waterland justifica que el paisaje natural (naturlandschaft) condiciona el paisaje cultural (kulturlandschaft) al decir que las aguas del Támesis podrían haber sido navegables hasta Flandes en otra época, por eso su paisaje resulta «familiar pero extraño». Es el mismo Swift quien verbaliza en dicha obra una realidad bien asentada en la cultura británica y es que «el agua que rodea a las islas es lo que, a lo largo de los siglos, permitió a Gran Bretaña permanecer intacta por el resto del mundo».

En poesía, Geoffrey Hill expresa el horror infligido por el Holocausto en un niño de once años (nacido 19.6.32 - deportado 24.9.42) ${ }^{6}$ Con estos versos, el poeta encuentra una vía de escape ante el horror a través de la observancia de la naturaleza, en parte como arraigo en lo natural, en parte como manera espiritual de elogio a lo que no es corruptible por la malicia humana. No solo se producen cronotopías, concepciones del conservadurismo y el regionalismo hacia el mapa, sino también hacia el rechazo del comportamiento humano con matices espirituales/religiosos. Tal es el caso de The Lord of the Flies (1954) de William Golding en el que se critica el «olvido» de las instituciones representativas, encarnación de las normas que nos rigen y nos llevan por el buen camino. Es una visión del pecado original que yace bajo un estilo de vida tolerante y acomodado. Esta no deja de ser una reflexión en parte sobre los horrores nazis y los bombardeos sobre Japón que el autor no pasa por alto e imprime en estas conclusiones. Golding se aferra a la necesidad de las normas sociales, al orden y la nobleza; quizás todas ellas espirituales o morales, sin las cuales los niños en aquella isla (en un mundo posapocalíptico) acaban sumidos en el desorden y la violencia.

Siguiendo esta línea de respeto por las normas y la moralidad tras la guerra como camino hacia la recuperación, Muriel Sparks escribe The Prime of Miss Jean Brodie (1961) donde la protagonista del relato sufre de forma arquetípica el mal de hibris (un exceso de autoconfianza). Casi todas las situaciones parece que son dadas, o bien merecidamente o procedente de un espanto añejo y tupido, casi inescrutable al que el niño «deportado» (metáfora de asesinado) de Geoffrey Hill ni siquiera se atreve a mirar. En el cine, el medio más consumido por el grueso de la población ${ }^{7}$ (además de la televisión) se hizo populares las comedias cinematográficas para subsanar estas terribles sensaciones. Se estrenaron también las Carry on Films de Gerald Thomas (Carry On sergeant (1958), Carry On screaming (1966)), destinadas a proyectar Gran Bretaña y el carácter británico en la gran pantalla; y las Ealing Comedies, como vía de escape entre el naturalismo, el realismo menos crudo y la huida a realidades más felices (Alexander Mackendrick, The Man in the White Suit

5 También los últimos victorianos ya se hacían eco de ello: por ejemplo Housman en Shropshire Lad (1896): Debemos respetar, si podemos respetar / estas leyes divinas y humanas, tan ajenas.

${ }^{6}$ September fattens on vines. Roses/ Flake from the wall. The smoke/ Of harmless fires drifts to my eyes. / This is plenty. This is more than enough.

7 Gran Bretaña era uno de los principales consumidores de cine durante los primeros años de la posguerra, aunque la irrupción del televisor en los hogares hizo que la venta de entradas cayera un 56\% entre 1946 y 1958. 
(1951), donde un solo traje pudo iluminar un espíritu apagado así como a todo lo que le rodeaba.

\title{
4. Unheimlich - Antagonismos fantasma
}

«Me niego a llorar por la muerte en un incendio de un niño en Londres» tituló Dylan Thomas a uno de sus poemas en 1946. Quizás es el poeta menos elegido para analizar por la intrincación de sus poemas, y sin embargo representa a la perfección esa melange de negritud, ruinas, muerte, inocencia perdida y dilemas de aprehensión del mal sufrido. Efectivamente, la delineación de aquello que infringió tanto daño humano resultó ser casi inaprehensible. Un incendio que mató a un niño y al que Dylan Thomas se niega a llorar:

\author{
Deep with the first dead lies London's daughter, \\ Robed in the long friends, \\ The grains beyond age, the dark veins of her mother, \\ Secret by the unmourning water \\ Of the riding Thames. \\ After the first death, there is no other.
}

Frente a lo afilado de la poesía de Thomas y aunque la poesía de Philip Larkin no sea sospechosa de ser mordaz o de enfrentar conceptos por definición reactivos casi químicamente, en su obra narrativa $A$ Girl in Winter (1947) juega hábilmente con la incomodidad del extranjero (de cuya experiencia nos hace partícipes) en una ciudad inglesa. La historia al completo es de una tibieza desconcertante. La protagonista, extranjera de procedencia desconocida, trabaja de bibliotecaria en una pequeña ciudad de Inglaterra durante la guerra. Mediante la narración de su experiencia años atrás en esa misma localidad nos prepara para la etapa final de la historia en la que, conservando esa tibieza gris, se reencuentra con el único amor platónico de su vida y al que rechaza en un gesto cercano al más puro estilo Kafka.

El extrañamiento propio de su naturaleza como extranjera y del recuerdo continuado de una época sin horror ni racionamiento, le causan casi tanta extrañeza como al propio lector que la asiste como en un parto sin recién nacido de por medio. Samuel Beckett y el mal llamado Teatro del Absurdo crean una realidad a partir de una extraña combinación de estilos: la expresión final es una concatenación de discontinuidades, momentos anticlimáticos e incomprensión; incomunicación en definitiva. Asistimos a la exaltación de la ausencia de Dios, frente al mensaje de necesidad de fe para la recuperación tras la guerra, o los gritos de conservadurismo en clave de enfrentamiento continuo de lenguaje e imagen; la futilidad de la vida, injusta y solitaria acompañada del pánico; un omnia mors aequat en vida. Siguiendo con el Teatro del Absurdo pero de una manera totalmente distinta, el papel que juega Harold Pinter ofrece una reflexión inclasificable puesto que su realismo no es identificable mediante la «negación de su contrario», es más, utiliza el enfrentamiento positivo, oponiendo la exageración de esa realidad con el humor desconcertante. 
El humor incrementa la sensación del miedo: sus escenarios van gestando la tensión y el miedo pero la llegada de un peligro - no denominado concretamente- nunca acaba de sobrevenirles ${ }^{8}$. Como se puede apreciar la muerte es un elemento recurrente y se enfrenta con lo imposible y reducido al absurdo o al humor de clase media, banaliza la causa orgánica de la muerte. El mal-némesis, sin ser aprehensible, no da códigos de conducta antagónica, sino que ofrece incomprensión y/o severidad en su hostigamiento.

La escena teatral fue el formato cultural más recurrente durante las primeras décadas de la posguerra, así, además de las mencionadas, las Kitchen Sink Drama aportaban el cinismo apabullante de esta época con irreverencias y atrevimiento sexual $^{9}$. Con el humor se ganó la batalla al tabú de posguerra (Comedy Taboo Films) con las figuras predominantes de Powell y Pressburger en Black Narcissus (1947) y The Red Shoes (1948), además de Michael Powell, David Lean, Ralph Thomas (entre muchos otros). Esta prohibición inconsciente parece que se fue deshaciendo a base de obras como las de Pinter, donde el humor era considerado «excéntrico» y «fuera de lugar»y, sin embargo, sumidos casi por completo en una sociedad de consumo y de cultura popular predominante entre el grueso de la población, una sola frase: «Don't mention the war» (Fawly Towers 1975) abrió la veda para que se pudiera hablar de la guerra con total libertad y en clave de humor sincero.

\section{Imperio}

Gran Bretaña era un coloso con extremidades dolorosas. Un imperio en «hipertensión» que poco a poco vislumbraba el fin de su gloria cuando Kipling ponía de relieve el entumecimiento de su regio imperio con los versos de su poema Recessional (1897): Lest we forget—lest we forget! (¡Ay como nos olvidemos!—¡Ay como nos olvidemos!). La obsesión por el imperio no pasa por ser un mero escupir de loores sino que se trata también, según ha demostrado la literatura británica, de encontrar esas maneras de ampliación del entramado de sus tejidos internos, pespuntes como ampliar el elenco de personalidades que compongan un panteón particular glorioso (esta práctica es válida tanto para el imperialismo cultural como para la aculturación o el hibridismo cultural) (Judt 2006: 337-353). Anthony Burgess puso estas premisas en práctica en su Earthly Powers (1980). Se trata de recordar de modo nostálgico épocas mejores, o tomar el pasado imperial para narrar un comportamiento imperialista con producciones distópicas. No es de extrañar, por tanto, la existencia de un gran volumen de distopías con críticas a las

${ }^{8}$ Max: ¡Un cadáver en mi sala! ;Lleváoslo! ¡Echadlo de aqui! / Joey: No está muerto /Lenny: Probablemente ha estado muerto durante 30 segundos / Max: ¡Ni siquiera está muerto! / Lenny: Sí, todavia respira un poco / Max: ¿Sabes lo que tenía este hombre? / Lenny: Lo que tiene. / Max: iTiene una imaginación enfermiza!

9 John Osborne (Look Back in Anger (1956) y Shelagh Delaney (A Taste of Honey (1958) sentaron las bases de referencia iconoclastas de una nueva generación por venir. 
instituciones del imperio heredado y aplicadas al Reino Unido como A Clockwork Orange (1962), donde la violencia institucional deshumaniza a la población joven ${ }^{10}$, orgullosa de su ultraviolencia que, por otra parte, se adapta perfectamente al escenario presentado: esa sociedad encarna todo aquello por lo que, irónicamente, castigan al joven DeLarge. No se volvió a retomar esta temática en unos años (1901-1960) en los que Gran Bretaña perdió 19 colonias $^{11}$ y su título de imperio quedaba más que en entredicho. Es más, son las propias independencias como acontecimiento histórico las que condicionan cierto comportamiento en la literatura y la expresión cultural británica.

Las expresiones culturales responden a la silueta de los procesos históricos. Entre las obras más importantes que dibuja estos aspectos está el Raj Quartet (19661975) de Paul Scott que narra el declive imperial en el Raj británico, con la violación de una joven como constante telón de fondo. Scott tiene claras influencias de E.M. Forster y su A passage to India (1924) y presenta a un prototipo de inglés desalmado, reprimido, pervertido y molesto. Las épocas gloriosas no se representan patronizadas por el dorado imperial, sino que son articuladas por las contradicciones humanas. Los diálogos antiimperialistas de los años 70s encuentran un paradigma en la caballería ligera que enviara Gran Bretaña durante la Guerra de Crimea (1853-1856). Existen dos películas con el mismo título: The Charge of the Light Brigade, una dirigida en 1936 por Michael Curtiz y otra dirigida en 1968 por Tony Richardson. Este ejemplo explica a la perfección cómo el objeto de temática «imperio» es codificado en clave política por la época en la que se produjera cada película. En una se ensalza el imperio (1936) y en la otra, antibelicista y antiimperialista, se critica precisamente todo lo que conlleva enviar a jóvenes a morir a un país lejano con el que no tienen mayor relación que los asuntos económicos de los políticos que les controlan (negligentemente). En las producciones literarias, la retrospección histórica de Gran Bretaña no es tan relacional, sino que el discurso es casi unidireccional $^{12}$. El Imperio ahora juega partidos de cricket contra sí mismo los domingos por la tarde.

\section{Enemigo interno}

Si el siglo XIX fue el siglo de las novelas como paradigma cultural, el siglo XX se caracteriza por transformar al relato en elemento activo reivindicatorio: esto se consigue en un marco histórico de constante cambio (desde 1945) a través de la

10 Doris Lessing expone una idea parecida en The Golden Notebook (1962) y Children of Violence (1952-1969) donde abunda el racismo colonial, el comunismo de posguerra y la amenaza nuclear.

${ }^{11}$ En este período de 1901 - 1960, Gran Bretaña perdió sus colonias más importantes: Egipto, Irlanda, Sudáfrica, Canadá, Australia, Iraq, India entre otras. En el período comprendido entre 1960 y 1980 , perdió un total de 35 colonias, un $61 \%$ del total de colonias que poseía al comenzar el siglo XX.

12 Esta literatura encuentra ejemplos entre Alan Bennett (The Old Country, 1978); Julian Mitchell (Another Country, 1981) o J.G. Farrell (Troubles, 1970, The Siege of Krishnapur, 1973 y The Singapore Crip, 1978). 
denuncia y la innovación inherentes al «relevo generacional» y a la transformación del mundo de posguerra. (Lindsay 2003: 137-141) Los orígenes de este formato hunden sus raíces en precedentes literarios en el período de entreguerras. Aunque de un alto status social -pero políticamente comprometidos- un nutrido grupo de jóvenes ${ }^{13}$ se obcecaban en acercar el advenimiento de la Modernidad a través de la literatura y la poesía.

Al acabar la Segunda Guerra Mundial esta lucha contra el «enemigo interno» - una designación orwelliana- toma dos formas de proceder: mediante la denuncia directa de la realidad social dada siguiendo cánones tradicionales y mediante rupturas abruptas con el modo de proceder tradicional de la expresión cultural en busca de una divergencia con los cánones preestablecidos. Casi como prólogo a todo un género, las novelas y ensayos de George Orwell (Animal Farm, 1945; 1984, 1949) se convirtieron en la Piedra Rosetta de la denuncia política y los análisis sociológicos: un cuaderno de bitácora para la izquierda inglesa más antijerárquica. Como denuncia a la realidad social dada, las formas de expresión fueron evolucionando al compás del momento histórico y la circunstancia política, creando «momentos privilegiados» para determinados subjects ${ }^{14}$.

La denuncia social se vio cristalizada por la particularidad de las realidades enfrentadas de la Gran Bretaña thatcherista y sobre todo por la desastrosa reubicación poblacional de trabajadores despedidos del sector industrial (Ohanian, 2002:23-30); una microsociedad decadente y apátrida que sufría la segregación horizontal en las urbes más importantes junto con una precarización de nivel de $v_{\text {vida }}{ }^{15}$. El otro gran paradigma comportamental es el de la ruptura procedimental abrupta en la forma de expresión literaria: desde los antirrománticos hasta el Free Cinema pasando por el Teatro del Absurdo. Se alcanzan en estos términos formas de expresión impensables sin el cambio generacional de posguerra. Los Angry Young Men (Kingsley Amis, Lucky Jim, 1954; Angus Wilson, No Laughing Matter, 1967, etc.) se centraron en la movilidad social y las diferencias de clase entre los trabajadores del norte y la clase media del sur de Inglaterra ${ }^{16}$. Con un propósito menos juvenil y sí más asentado en el método de la Alta Kultura (con «k»)

13 W.H. Auden, Stephen Spender, C. Day Lewis, Louis MacNeice, entre otros.

14 Tal es el caso del feminismo a finales de la década de los 70s (Angela Carter The Bloody Chamber and other Stories, 1979; Doris Lessing Canopus in Argos, 1979-83) o la denuncia de abusos laborales de los 80s y las «Radical Left Playwrights» (Caryl Churchill, Serious Money, 1987; David Hare, Murmuring Judges, 1991; Dennis Potter, The Singing Detective, 1986; Alan Bennet, A woman of no importance, 1982.)

15 Estos rasgos se hacen patentes en la llamada «Industrial Poetry» de Tony Harrison (The Loiners, 1970; From the School of Eloquence and Other Poems, 1978; The Blasphemers Banquet, 1989) y en las novelas conocidas por reflejar «la condición de Inglaterra» (David Lodge, Nice Work, 1988; Martin Amis, Money, 1984; Margaret Drabble, The radiant Way, 1987.)

16 Estas obras se caracterizan por tener un buen número de publicaciones en formato secuencia (once novelas en secuencia de C.P. Snow, Strangers and Brothers, 1940-1970; doce novelas en secuencia de Anthony Powell, A Dance to the Music of Time, 1951-75) lo que rompe con la excepcionalidad del relato único contenido en una sola novela, encajando así con el público objetivo al que iban destinadas. 
destacan los llamados Antiromantics Philip Larkin (Jill, 1946; A Girl in Winter, 1947; The Less Deceived, 1955) y Ted Hughes (The Hawk in the Rain, 1957; Crow, 1970; Moortown, 1979) entre otros. Caracterizados todos ellos por utilizar la ironía para mostrar su rechazo con los dogmas del «buen proceder» del arquetipo de poeta.

Como añadido final a este apartado es necesario resaltar la importancia del Free Cinema como expresión revolucionaria por innovadora: una mezcla de experimentalidad, cine y documental en el que la temática no es tan necesaria como la exigencia de romper con la forma de relatarla, por ejemplo Karel Reisz con Momma won't allow (1956). El Free Cinema bien puede ser clasificado como un antecedente de la Nouvelle Vague francesa o el Oberhausen Manifesto alemán.

\section{Conclusión}

La excepcionalidad de la vivencia de los acontecimientos históricos de Gran Bretaña durante la primera mitad del siglo XX requiere estudios comportamentales no solo de sus acontecimientos históricos sino también de las expresiones culturales de los que derivan y con los que se interrelacionan. La opinión británica genera una particularidad propia de acontecimientos previos a la Segunda Guerra Mundial, como admitir que el Great Slump (la Gran Depresión) tuvo rasgos especiales para Gran Bretaña y sin embargo se conciba otro momento histórico como parte de una generalidad sin cuestionamiento alguno sobre si la insularidad -nunca mejor dichodefendida en el caso anterior seguiría o no vigente y por qué. El Blitz generó ciertos rasgos traumáticos en un imperio que ya traía lacras consigo en una sociedad que los confirmaba como síntomas de una enfermedad secular. La cultura británica tuvo un Blitz cultural-comportamental que desarrollaría, como siempre lo ha hecho, al otro lado del Canal de la Mancha.

\section{Referencias bibliográficas}

ALDERMAN, Nigel y BLANTON C.D. (eds.) (2014): A concise companion to postwar British and Irish poetry. Malden, Massachussets: Wiley-Blackwell.

CASERIO, Robert L. (ed.) (2009): The Cambridge companion to the twentieth-century English novel. Cambridge: Cambridge University Press.

FIELD, Geoffrey (2002): «Nights underground in darkest London. the Blitz, 1940-1941». International Labor and Working-Class History 62: 11-49.

FISHER, Katherine E. (2014): Writing (in) the Spaces of the Blitz: Spatial Myths and Memory in Wartime British Literature (Tesis inédita). Michigan: University of Michigan.

HobsBawm, Eric (2001): Industria e Imperio. Madrid: Ed. Crítica.

Judt, Tony (2006): Posguerra: una Historia de Europa desde 1945. Madrid. Taurus.

LINDSAY, Craig (2003): «A century of labour market change: 1900 to 2000». Labour Market trends. Palgrave MacMillan Journals Marzo.

OHANIAN, Lee E. (2002): «The Great U.K. Depression: a Puzzle and a Possible Resolution» Review of Economic Dynamics Vol. 5, 1: 19-44. 


\section{Recursos web:}

«The Blitz.» 1940: London's Finest Hour. Imperial War Museum, 2010. Web. 23 Noviembre de 2013.

MURROW, Edward R., The London Blitz of 1941 (recurso de audio), en https://archive.org/details/EdwardR.Murrow-LondonBlitz1940 [Consulta: 01/ 2016]. 